\title{
Stress Analysis of Gas Pipeline Under Seismic Action in Tunnel
}

\author{
Liqiong Chen ${ }^{1}$, Xiaoyu $\mathrm{Han}^{1 *}$, Yuchao Chen ${ }^{1}$, Yu Lu${ }^{1}$, Jie Xu${ }^{2}$, Lingxiao $\mathrm{Li}^{3}$ \\ ${ }^{1}$ School of Petroleum Engineering, Southwest Petroleum University, Chengdu, Sichuan,China \\ ${ }^{2}$ NO. 2 Mud Logging Company, BHDC, Renqiu, Hebei, China \\ ${ }^{3}$ College of Chemistry and Chemical Engineering, Southwest Petroleum University, Chengdu, Sichuan, China
}

\begin{abstract}
Nowadays, the stress analysis mostly aimed at general buried pipelines. And few of the gas pipelines in tunnel (especially under the seismic action) were analyzed. Therefore, it is necessary to analyze the stress distribution of gas pipeline under seismic action in tunnel. In this paper, CEASAR II software was used to establish the stress model of China-Myanmar XX tunnel pipeline under seismic action, based on the seismic spectrum. A pipeline dynamic stress analysis was performed by inputting spectral parameters of gas pipeline, and the results indicated whether or not the pipeline displacement and stress under a violent seismic action would conform to specification. We came to that: (1) In general, the most dangerous section of the pipe is the bend. Measures to control stress should be taken to reduce the stress. (2) Axial seismic action and comprehensive seismic action effected by greater impact on pipelines. Therefore, the stress variation at the axial seismic and comprehensive seismic action should be focused on. (3) Through the displacement checking of the pipeline, the effect of axial seismic action and comprehensive seismic action to displacement was larger. (4) Unlike buried pipeline, the axial displacement was large compared to other two direction displacement. And strengthening the monitoring efforts was necessary.
\end{abstract}

Keywords: Tunnel, gas pipeline, seismic, stress analysis, CEASAR II, spectrum analysis.

\section{INTRODUCTION}

China-Myanmar oil and gas pipeline is one of the major pipeline projects in China. It is also the fourth largest energy importer channel after the Central Asian oil and gas pipelines, the China-Russia crude oil pipeline and the sea channel being completed. With dramatic characteristics, like frequent seismic activity and highly earthquake intensity, the tunnel crossing engineering is used to cross complex mountains. Pipeline under the action of a strong earthquake is more likely to have been severely disrupted, especially the pipeline without seismic design and seismic reliability analysis. Therefore, how to ensure pipeline safe and reliable under the possibility seismic action in the future and improve the seismic performance of this pipeline has become the urgent task to engineering design and management departments [1-3].

Stress analysis can meet the requirements of pipeline design strength and flexibility, and ensure the safety of the pipeline under various conditions. For ensuring pipeline safety operation and reducing the security hidden danger, to carry out the stress analysis of pipeline under seismic action is of great significance to design of pipeline, operational safety and engineering construction [4].

*Address correspondence to this author at the School of Petroleum Engineering, Southwest Petroleum University, Chendu, Sichuan, China;

E-mail: hanxiaoyuswpu@126.com
During the 1930s, researchers applied structure mechanics to analyze and solve the pipeline's internal force $[5,6]$. To improve the calculation accuracy, a calculation method based on an indeterminate structure was used to solve the pipeline's internal force and taking into account both the uniform load and concentrated load on the pipeline. Then, in the 1960s, the longitudinal displacement was founded that it had great effect on buried pipelines [7]. The former Soviet Union's Bukhara-Ural Large Diameter Gas Transportation Pipeline's design was based on the assumption that the gas transportation pipeline would be fully constrained by the surrounding soil.

In recent years, scholars have increasingly taken the stress analysis of piping which must be carried out to ensure the safety. In 2012, Hu Meilin analyzed the stress variation of gas pipeline in sloping tunnel [8]. In 2012, Huang Kun's stress analysis model elastic laying pipelines should be used in mountainous area [9]. Since 2013, many scholars have paid special section on the pipe stress special conditions analysis, including through the swamp section, landslide area and fault area. However, there is little research about stress and displacement of gas pipelines under the seismic action in tunnel.

In this paper, CEASAR II software was used to analyze the stress and displacement of China-Myanmar XX tunnel pipeline under seismic action based on the theory of seismic spectrum analysis method and finite element analysis. 


\section{THEORY AND METHOD}

\subsection{Spectrum Analysis Method}

Nowadays, the methods of stress analysis of pipeline under seismic action mainly include static analysis (the elastic static method and the static elastoplastic analysis method) and dynamic analysis (the seismic spectrum analysis method and time history analysis method) [10, 11]. Considering the structure dynamic characteristics and the relationship between the ground motion characteristics and application of the static theory fully, the spectrum analysis uses the static theory method to turn dynamic motion to static analysis subtly. In this way, it makes the complex seismic action simple, and the calculation of effect became easily [12]. In engineering calculation, for more regular structure, the spectrum analysis method is generally used. Besides, if the condition of precision meets the requirements of analysis, spectrum analysis method is simpler than the time history analysis method.

Spectrum designing and values of the spectrum are usually with reference to the ASCE 7 "Minimum Design Loads for Buildings and Other Structures" $[13,14]$ of the American Society of Civil Engineers. Compared with GB 50011 "Code for Seismic Design of Buildings" [15], it is more conservative.

\subsection{Standards for Stress and Displacement of Pipelines}

(1) Checking of stress Earthquakes is random, which belongs to the occasional load cases. According to the regulation of B31.8 [16] , axial stress produced by occasional load may not exceed the product of the minimum yield strength and temperature coefficient, giving:

$\sigma \leq F \sigma_{s}$

where, $\mathrm{F}=1.0$ for gas pipelines

(2) Checking displacement: The checking of displacement mainly aimed at the lateral displacement and axial displacement. According to GB 50251 "Code for Design of Gas Transmission Pipeline” [17] and GB 50316 "Design Specification for Industrial Metal Piping" [18], they require that the lateral displacement shall not be more than 0.03 times of diameter, which is

$\Delta x_{L} \leq 0.03 D$ where $\Delta x_{L}$ is the maximum lateral displacement of the steel pipeline, $\mathrm{m}$; and $D$ is the average diameter of the steel pipeline, $\mathrm{m}$.

And axial displacement shall not be more than 0.4 times of the length of the pipe bracket, which is

$\Delta x_{A} \leq 0.4 B$

Where, $\Delta \boldsymbol{x}_{\boldsymbol{A}}$ is the maximum axial displacement of the steel pipeline, $\mathrm{m}$; and $B$ is the length of the pipe bracket, $\mathrm{m}$.

\section{CASE STUDY}

\subsection{Project Introduction}

The China-Myanmar pipeline is located in the Hengduan Mountains and the Yunnan-Guizhou plateau. Because of the complex terrain, there are a lot of mountain tunnels, of which the total length is $81 \mathrm{~km}$. Near the tunnel, the karst development is strong. There are about 17 tunnels appearing this kind of phenomenon. The surrounding rocks of tunnel are poor, and the grade- $\mathrm{V}$ and VI surrounding rocks are more than $50 \%$ of the total length of tunnel. The tunnels of watery surrounding rocks are more than $90 \%$. More than $70 \%$ of the tunnels are located in high ground stress area. Most tunnels are situated in high earthquake intensity area where the earthquake magnitude is higher than VII degrees [3].

The length of China-Myanmar XX tunnel is about 1.9 $\mathrm{km}$. Gas pipeline in tunnel adopts the method of laying pipeline overhead.[19] The pipe frame is set every $10 \mathrm{~m}$ and the friction coefficient between the block and pipeline is 0.6. To truncate the influence of the outer pipe tunnel, fixed pier 1 and 2 are set, respectively. Along the direction of fluid flow, the tunnel inlet has a $15 \mathrm{~m}$ long horizontal line. Then followed by a steep slope in the tunnel laying pipeline, the slope angle is $23.27^{\circ}$. The slope angle of the last two pipes of which angle are smaller are $7.43^{\circ}$ and $6.17^{\circ}$, and the length of the pipe are $540 \mathrm{~m}$ and $585 \mathrm{~m}$ respectively. Piping schematic diagram is shown in Fig. (1) [19] and the longitudinal profile of pipeline in tunnel is shown in Fig. (2). Earthquake intensity is 9 degrees, and the basic seismic acceleration is $0.4 \mathrm{~g}$.

X80 steel pipe is used for the gas pipeline, the running temperature is $38^{\circ} \mathrm{C}$ and the operating pressure is $10 \mathrm{MPa}$. The parameters of pipeline and bends are shown in Table $\mathbf{1}$ and Table 2 respectively [20].

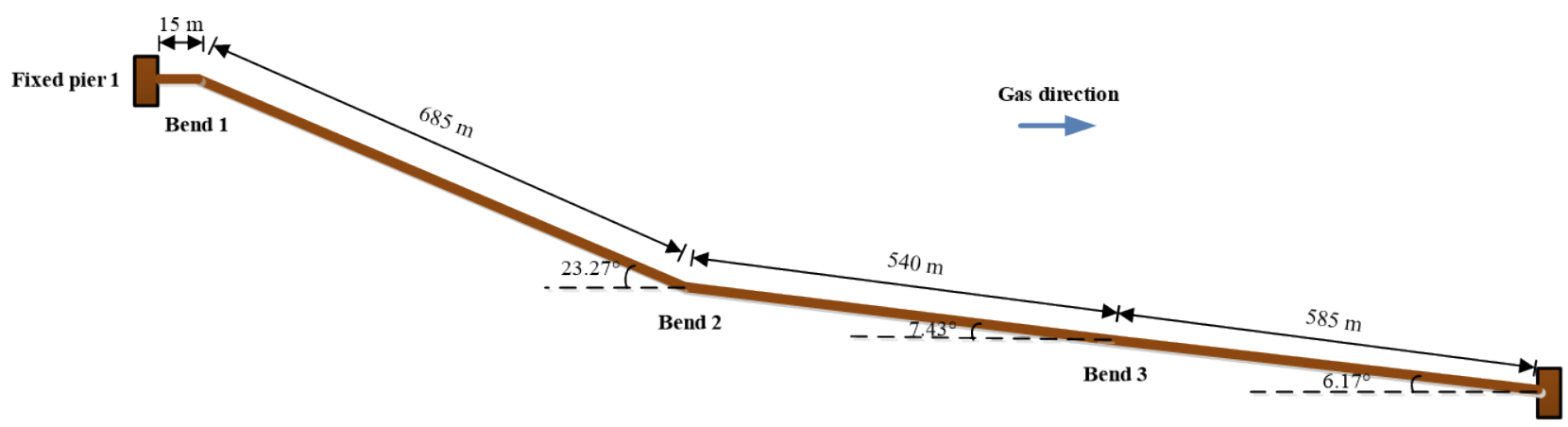

Fig. (1). The schematic of pipeline in tunnel [19]. 


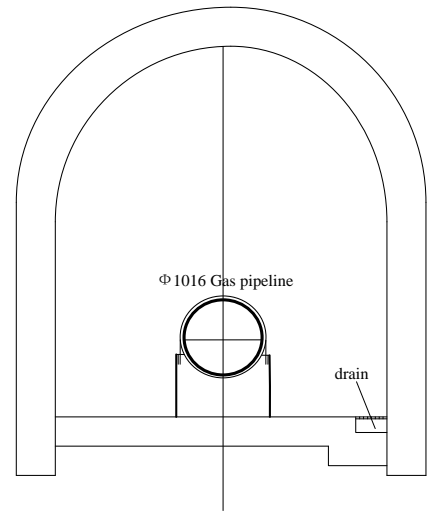

Fig. (2). The longitudinal profile of tunnel.

\subsection{Seismic Analysis and Load Combinations}

According to the China-Myanmar XX tunnel construction and seismic data, the parameters of the required value in spectrum analysis would be detected from GB50011 "Code for Seismic Design of Buildings" [15] and ASCE7-05 [14], as shown in Table 3 , where the $F_{\mathrm{a}}$ and $F_{\mathrm{v}}$ are site coefficient, $S_{\mathrm{s}}$ is acceleration of short cycle design response spectrum, $S_{1}$ is acceleration of one second cycle design response spectrum. The spectrum analysis results responded by CEASAR II are shown in Fig. (3), and the load combinations are shown in Table 4.

\subsection{Boundary Condition}

Due to the large displacement of pipeline in tunnel, fixed pier needs to set for a pipeline on both sides to limit the influence on movement of the buried pipeline. The

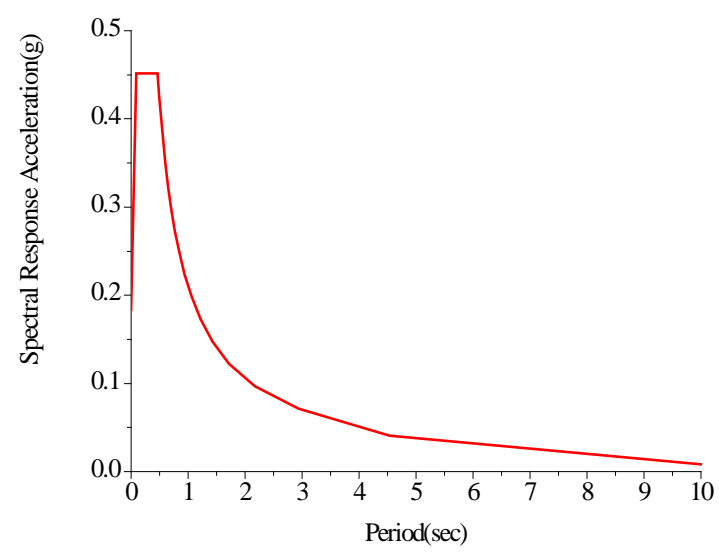

Fig. (3). Analytic result of response spectrum.

displacement of either side on pipeline is mutually independent, and the change of stress cannot pass through fixed pier. So, the fixed pier on either side of the pipeline is the boundary of the model.

\section{RESULTS AND DISCUSSION}

\subsection{Stress Analysis}

CEASAR II software was used to analyze the dynamic stress for gas pipelines under seismic action in the tunnel, then stress, displacement, constraints conditions were output. Table 5 shows the stress checking of the gas pipeline under seismic action, where the ratio represents the percentage of stress value and the allowed stress value. And the stress distribution is given in Fig. (4).

Table 1. Parameters of pipeline [20].

\begin{tabular}{|c|c|c|c|c|c|c|c|c|}
\hline Pipeline & Material & Diameter/mm & $\begin{array}{c}\text { Wall } \\
\text { thickness of } \\
\text { straight } \\
\text { pipe/mm }\end{array}$ & $\begin{array}{c}\text { Wall } \\
\text { thickness of } \\
\text { Pipe } \\
\text { bend/mm }\end{array}$ & $\begin{array}{c}\text { Temperature } \\
\left({ }^{\circ} \mathrm{C}\right)\end{array}$ & Pressure/MPa & $\begin{array}{c}\text { Fluid } \\
\text { density } / \mathrm{kg} / \mathbf{m}^{3}\end{array}$ & $\begin{array}{c}\text { Minimum } \\
\text { yield stress } \\
\text { /MPa }\end{array}$ \\
\hline Gas & X80 & 1016 & 22.9 & 26.4 & 38 & 10 & 0.784 & 551 \\
\hline
\end{tabular}

Table 2. Parameters of bends [20].

\begin{tabular}{|c|c|c|}
\hline Bend & Type & Remark \\
\hline \hline Bend 1 & Hot bending elbow & $\mathrm{R}=6 \mathrm{D}$ \\
\hline Bend 2 & Hot bending elbow & $\mathrm{R}=6 \mathrm{D}$ \\
\hline Bend 3 & Cold bending elbow & $\mathrm{R}=40 \mathrm{D}$ \\
\hline
\end{tabular}

Table 3. Parameters of response spectrum [14, 15].

\begin{tabular}{|c|c|c|c|c|c|}
\hline \multirow{2}{*}{$\begin{array}{c}\text { The most important } \\
\text { coefficient of component }\end{array}$} & \multicolumn{2}{|c|}{ Site coefficient } & \multirow{2}{*}{$\boldsymbol{S}_{\mathrm{s}}$} & $\boldsymbol{S}_{\mathbf{1}}$ & \multirow{2}{*}{ Response modification factor } \\
\cline { 2 - 6 } & $\boldsymbol{F}_{\mathrm{a}}$ & $\boldsymbol{F}_{\mathbf{v}}$ & 1.58 & 0.46 & 3.5 \\
\hline \hline 1.5 & 1.0 & 1.3 & .36 \\
\hline
\end{tabular}


Table 4. Load combinations.

\begin{tabular}{|l|c|c|}
\hline \multicolumn{1}{|c|}{ Operating conditions } & Representation in CAESAR II & Remark \\
\hline \hline Static continuous condition & $\mathrm{W}+\mathrm{P}$ & A result of gravity and pressure \\
\hline Axial seismic action & $\mathrm{W}+\mathrm{P}+\mathrm{D}_{1}$ & - \\
\hline Lateral seismic action & $\mathrm{W}+\mathrm{P}+\mathrm{D}_{2}$ & - \\
\hline Longitudinal seismic action & $\mathrm{W}+\mathrm{P}+\mathrm{D}_{3}$ & - \\
\hline Comprehensive seismic action & $\mathrm{W}+\mathrm{P}+\mathrm{D}_{1}+\mathrm{D}_{2}+\mathrm{D}_{3}$ & The combination of three direction seismic action \\
\hline
\end{tabular}

Table 5. Stress check of gas pipeline.

\begin{tabular}{|c|c|c|c|}
\hline Pipeline & Maximum peak stress /MPa & Requirement/MPa & Ratio (\%) \\
\hline \hline Gas & 441.95 & 555 & 79.63 \\
\hline
\end{tabular}

According to Table 5 and Fig. (4), the following can be concluded:

1. The stress of tunnel pipeline under seismic action conforms to the requirements.

2. The dangerous section of this gas pipeline is bend 2, which is the tunnel at the bottom of a steep hill.

3. For tunnel pipeline, axial seismic action and comprehensive seismic action have a greater influence on the pipe. Therefore, checking of stress under the action of an axial seismic and comprehensive seismic should be focused on pipe, and the monitoring efforts should be strengthened.

4. Bend 1 and bend 2 are steep slope section of tunnel. Along the flow direction, stress decreases gradually, and highly increased in bend 2 .

\subsection{Checking of Displacement}

Table 6 shows the displacement variation of gas pipeline in tunnel under the different action of seismic. Fig. (5) to Fig. (7) show the distribution of displacement under the action of axial, lateral and longitudinal seismic.

According to Table 6 and Fig. (5) to Fig. (7), the following can be concluded:

1. According to the requirement of the axial displacement and lateral displacement in GB50251 and GB50316, the axial displacement and lateral displacement of gas pipeline in tunnel conform to the requirements.

2. In displacement of these three seismic directions, axial displacement is maximal and the lateral displacement is minimal. However, according to the study of $\mathrm{Wu}$ Xiaonan [13], to buried pipeline, lateral displacement is maximal under seismic action. The reason why displacement of gas pipeline in tunnel is different from buried pipeline is that gas pipeline in tunnel is restrained by brackets that restrict the lateral displacement.

3. It is important to check the axial displacement of gas pipeline in tunnel, and especially the efforts that restrict the lateral displacement should be strengthened.

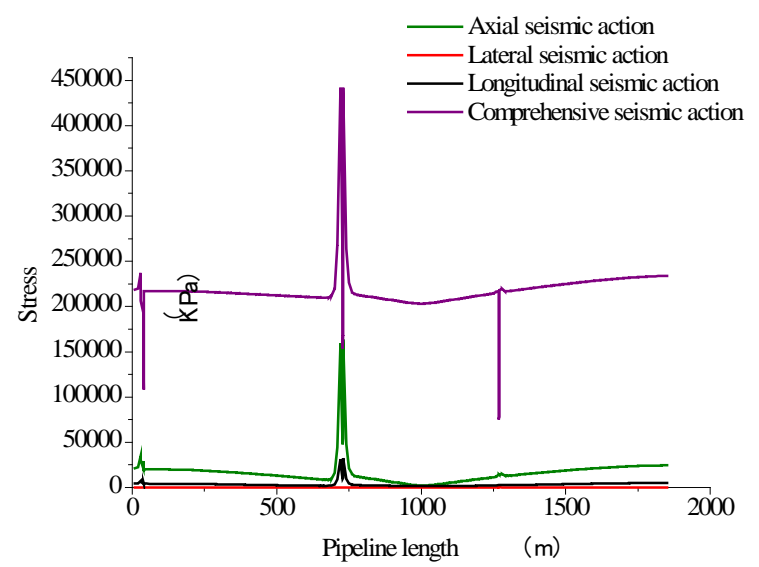

Fig. (4). Stress distribution of gas pipeline under seismic action.

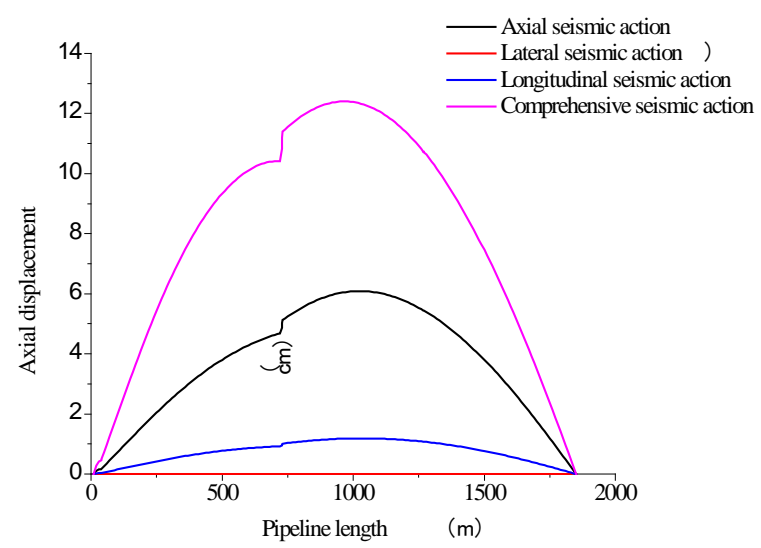

Fig. (5). Axial displacement distribution of gas pipeline.

4. The axial seismic action and comprehensive seismic action have great impact on displacement of gas pipeline. It should be monitored.

5. From Fig. (5) to Fig. (7), without any supports set in bend 2 and bend 3, the displacements are changing dramatically under seismic action. In Fig. (5), the axial 
Table 6. Displacement check of gas pipeline in tunnel.

\begin{tabular}{|c|c|c|c|c|c|c|}
\hline \multirow{2}{*}{ Pipeline } & \multicolumn{2}{|c|}{ Axial displacement/cm } & \multicolumn{2}{c|}{ Longitudinal displacement/cm } & \multicolumn{2}{c|}{ Lateral displacement/cm } \\
\cline { 2 - 7 } & Maximum & Requirement & Maximum & Requirement & Maximum & Requirement \\
\hline \hline Gas & 12.40 & 60 & 4.47 & - & 0.0015 & 3.05 \\
\hline
\end{tabular}

Remark: The length of pipe frame is $1.5 \mathrm{~m}$.

displacement at bend 2 soars but in Fig. (6), the longitudinal displacement falls dramatically. The reason is that the flexibility of bend is large and its lack of axial support, the axial displacement soars under the action of both ends fixed support. However, under the extrusion of both ends fixed, bend, the longitudinal displacement falls dramatically with the upward trend.

6. Because the slope angle of bend $2\left(23.27^{\circ}\right)$ is larger than that of bend $3\left(7.43^{\circ}\right)$, through synthesis and decomposition of the movement, the trend of displacement change of bend 2 is more obvious. So, in Fig. (5) and Fig. (6) the displacement of bend 3 (about $1240 \mathrm{~m}$ ) change slowly. Moreover, the angle of bend 3 is smaller (similar to the straight pipe), the axial displacement changes smoothly. But the flexibility of bend still existed, so through synthesis and decomposition of the movement, the longitudinal displacement has a less obvious jump.

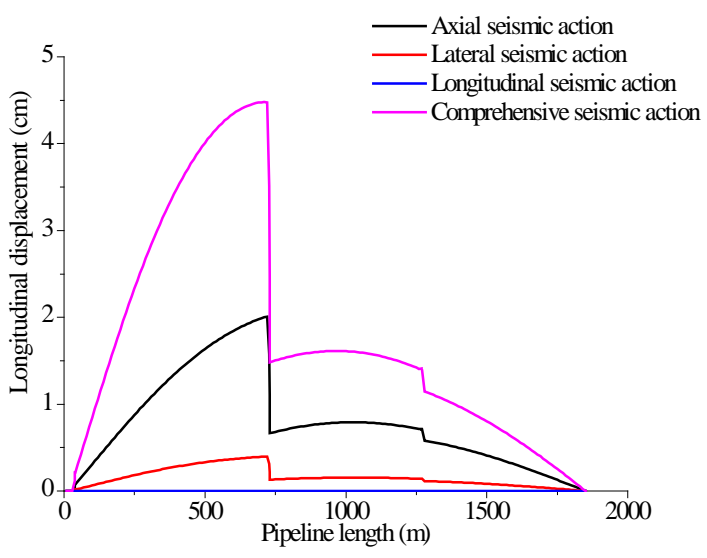

Fig. (6). Longitudinal displacement distribution of gas pipeline.

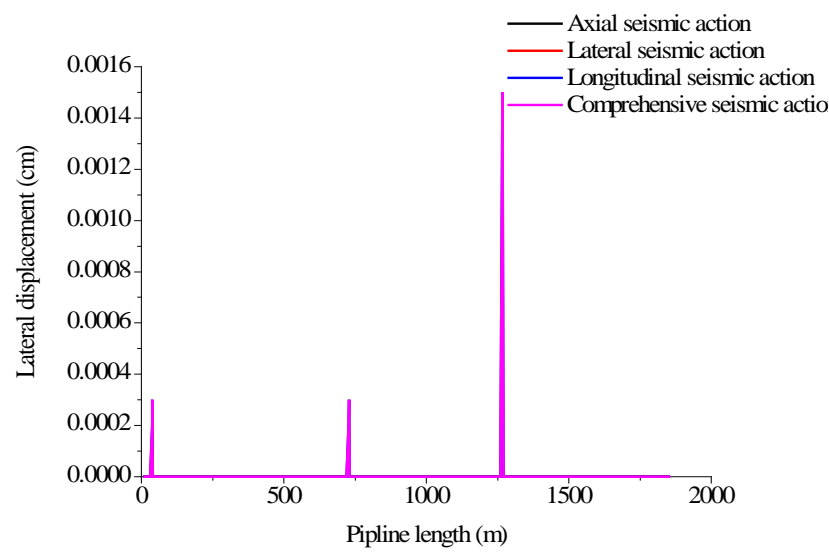

[3] X. J. Wang, Y. J. Chen, and Z. F. Yu, "Construction difficulties and technical innovation of the Myanmar-China Oil and Gas Pipeline”, Oil \& Gas Storage and Transportation, vol. 33, pp. 1039-1046, 2014.

[4] Z. F. Sui, "The Stress Analysis of Special Pipe Section and Safety Study of the Gas Pipeline", M.S. thesis, China University of Petroleum, Beijing, China, 2009.

[5] R. K. Watkins, and L. R. Anderson, Structural Mechanics of Buried Pipes, CRC Press: Boca Raton, 1999.

[6] G. Q. Yu, and Z. H. Lv, "Load calculation and analysis of heating pipeline based on elastic center method”, Gas and Heat, vol. 28, pp. 20-24, 2008.

[7] B. B. Rajani, P. K. Robertson, and N. R. Morgenstern, "Simplified design methods for pipelines subject to transverse and longitudinal soil movements”, Canadian Geotechnical Journal, vol. 32, pp. 309-323, 1995.

[8] M. L. Hu, Stress Analysis of Gas Pipeline in Sloping Tunnel, Southwest Petroleum University, Chengdu, 2012.

[9] K. Huang, S. J. Wu, and H. F. Lu, "Stress analysis of the pipeline laid along the slope”, Natural Gas and Oil, vol. 33, pp. 1-4, 2012.

Fig. (7). Lateral displacement distribution of gas pipeline. 
[10] S. W. Zhan, and W. G. Wang, Large Span Pipeline Suspension Crossing Design and Construction, Petroleum Industry Press, Beijing, 2013.

[11] W. Wang, "The Comparative Analysis of Response Spectrum Method and Time Analysis Method in Anti-seismic Design of Tall Building", M.S thesis, South China University of Technology, Guangdong, China, 2012.

[12] Q. L. Liu, "Research and Improvement on Traditional Response Spectrum CQC Method", M.S. thesis, Zhejiang University, Zhejiang, China, 2007.

[13] X. N. Wu, H. F. Lu, and K. Huang, "Stress analysis of gas pipelines at seismic belts based on the spectrum analysis", Natural Gas Industry, vol. 34, pp. 152-157, 2014.

[14] ASCE, "ASCE 7-05 Minimum Design Loads for Buildings and Other Structures", American Society of Civil Engineers Press, Reston, Virginia, 2005.
[15] GB 50011. Code for Seismic Design of Buildings. China Planning Press, Beijing, 2010.

[16] ASME. 2012c. ASME B31.8 Gas Transportation and Distribution Piping Systems. American Society of Mechanical Engineers Press, NY, 2012.

[17] GB 50251. Code for Design of Gas Transmission Pipeline, China Planning Press, Beijing, 2003.

[18] GB 50316. Design Code for Industrial Metallic Piping. China Planning Press, Beijing, 2008.

[19] H. Shi, Z. H. Zeng, and L. B. Zuo, "Overall design of Lantsang bridge and tunnel crossing project for the Myanmar-China Oil and Gas Pipeline”, Oil \& Gas Storage and Transportation, vol. 33, pp. 1034-1038, 2014.

[20] S. W. Zhan, Y. J. Feng, and X. Z. Wu, "Feasibility analysis on the overhead crossing in one pipe-bridge for Sino-Myanmar Oil/Gas Pipelines”, Oil \& Gas Storage and Transportation, vol. 30, pp. 827-829, 2011.

Received: September 17, 2014

(C) Chen et al.; Licensee Bentham Open.

This is an open access article licensed under the terms of the Creative Commons Attribution Non-Commercial License (http://creativecommons.org/licenses/ by-nc/3.0/) which permits unrestricted, non-commercial use, distribution and reproduction in any medium, provided the work is properly cited. 